\title{
Genome Sequence Resources for the Maize Pathogen Fusarium temperatum Isolated in Poland
}

\author{
Marcin Wit, ${ }^{1}$ Yueqiang Leng, ${ }^{2}$ Yang Du, ${ }^{3}$ Małgorzata Cegiełko, ${ }^{4}$ Emilia Jabłońska, ${ }^{1}$ Wojciech \\ Wakuliński, ${ }^{1, \dagger}$ and Shaobin Zhong ${ }^{2, \dagger}$ \\ ${ }^{1}$ Department of Plant Protection, Institute of Horticultural Sciences, Warsaw University of Life Science, \\ 02-776 Warsaw, Poland \\ ${ }^{2}$ Department of Plant Pathology, North Dakota State University, Fargo, ND 58108, U.S.A. \\ ${ }^{3}$ Department of Computer Systems and Software Engineering, Valley City State University, Valley City, \\ ND 58072, U.S.A. \\ ${ }^{4}$ University of Life Sciences in Lublin, 20-950 Lublin, Poland
}

\section{Abstract}

Fusarium temperatum (Scaufl. \& Munaut) is one of the most important fungal pathogens that cause ear and stalk rots in maize. In this study, we sequenced genomes of two F. temperatum isolates (KFI615 and KFI660) isolated from corn ears in Poland. A total of 110.3 and 116.3 million 100-nucleotide paired-end clean reads were obtained for KFI615 and KFI660, which were assembled into 20 and 18 scaffolds with an estimated genome size of 45.21 and 45.00 $\mathrm{Mb}$, respectively. These genome sequences provide important resources for understanding pathogenicity and biology of the pathogens within the Fusarium fujikuroi complex.

\section{Genome Announcement}

Fusarium species are among the notorious pathogens that cause destructive diseases in many different plant species worldwide (Kvas et al. 2009). Phylogenetic analyses based on DNA sequences revealed monophyletic lineages consisting of 20 species complexes within the Fusarium genus (Ma et al. 2013). Among them is the Fusarium fujikuroi species complex (FFSC), which contains over 50 distinct species that group into three clades, the American, African, and Asian clades (O'Donnell et al. 1998). Fusarium temperatum is one of the members in FFSC (Scauflaire et al. 2011). This fungus was formerly classified as $F$. subglutinans group I, but, later, it was formally named as a new species (Scauflaire et al. 2011), with the F. subglutinans group II remaining in F. subglutinans sensu stricto (De Vos et al. 2014; Desjardins 2006; Moretti et al. 2008; Steenkamp et al. 2002). F. temperatum not only causes yield losses but also produces mycotoxins in maize (Fumero et al. 2020; Scauflaire et al. 2011). Whole genome sequences have been available for two $F$. temperatum isolates, one from Mexico (CMW40964) (Wingfield et al. 2015) and the other from Argentina (RC2914) (Fumero et al. 2020). However, no genome sequences have been reported for

${ }^{\dagger}$ Corresponding authors: W. Wakuliński; wojciech_wakuliński@sggw.edu.pl and

S. Zhong; shaobin.zhong@ndsu.edu

*The $e$-Xtra logo stands for "electronic extra" and indicates there are supplementary materials published online.

Marcin Wit and Yueqiang Leng made equal contribution to this work.

The author(s) declare no conflict of interest.

Accepted for publication 15 October 2020.

\section{$e-$ tra* $^{*}$}

\section{Funding}

A portion of this research was supported by the "Basic Research for Biological Progress in Crop Production" Program sponsored by the Polish Ministry of Agriculture and Rural Development (task no. 92) to M. Wit and the United States Wheat \& Barley Scab Initiative Program sponsored by the United States Department of Agriculture (agreement no. 59-0206-0162) to S. Zhong.

\section{Keywords}

ear rot disease, fungal pathogen, Fusarium temperatum, genome, maize 
Table 1. Summary of genome sequencing and assembly statistics for Fusarium temperatum isolates KFI615 and KFI660

\begin{tabular}{|c|c|c|}
\hline Genomic features & KFI615 & KFI660 \\
\hline \multicolumn{3}{|l|}{ Genome sequencing } \\
\hline Sequencing platform & BGI500 & BGI500 \\
\hline Number of reads & $110,319,180$ & $116,335,522$ \\
\hline Read length (bp) & 100 & 100 \\
\hline Coverage $(x)$ & 243 & 256 \\
\hline \multicolumn{3}{|l|}{ Assembly statistics } \\
\hline Total genome size $(b p)^{a}$ & $45,212,390$ & $44,997,458$ \\
\hline Number of contigs ${ }^{b}$ & 4689 & 5615 \\
\hline Number of scaffolds ${ }^{c}$ & 20 & 18 \\
\hline GC content & $46 \%$ & $47 \%$ \\
\hline $\mathrm{N}_{50}(\mathrm{bp})^{\mathrm{d}}$ & $4,476,538$ & $4,452,916$ \\
\hline $\mathrm{L} 50^{\mathrm{e}}$ & 5 & 5 \\
\hline BUSCO completeness $(\%)^{f}$ & $98.90 \%$ & $99.00 \%$ \\
\hline \multicolumn{3}{|l|}{ Annotation statistics } \\
\hline Genes $^{\mathrm{g}}$ & 14,067 & 13,994 \\
\hline Secondary metabolism key enzymes ${ }^{\mathrm{h}}$ & 49 & 50 \\
\hline Carbohydrate-active enzymes ${ }^{i}$ & 588 & 586 \\
\hline Secreted proteins ${ }^{j}$ & 1,471 & 1,474 \\
\hline Candidate effectors ${ }^{k}$ & 328 & 325 \\
\hline
\end{tabular}

a Estimated by summing the lengths of all assembled scaffolds.

b Generated using the ABySS v2.0 assembly program with $\mathrm{k}=84$.

c Generated utilizing the RaGoo program with F. temperatum CMW 40964 as reference.

${ }^{d}$ Length of the smallest scaffold in an ordered set of scaffolds corresponding to $50 \%$ of the genomes total size.

e Smallest number of scaffolds whose length equals $50 \%$ of the genome total size.

${ }^{f}$ Evaluated using the BUSCO v4.1.2 program with the ascomycota core gene set.

$g$ Predicted by the AUGUSTUS program with gene models of $F$. graminearum as training sets.

$\mathrm{h}$ Predicted by the antiSMASH fungal version program.

i Predicted by dbCAN2.

j Predicted by SignalP 5.0.

k Predicted by Effector 2.0.

F. temperatum isolates isolated from continents other than South America. Availability of genome sequences from diverse isolates of the species will allow for comparative genomics studies, which may facilitate the identification of genes for pathogenicity and other traits related to plant infection.

Two F. temperatum isolates, KFI615 and KFI660, were isolated from corn ears in Radzików, Mazovia Province, Poland. KFI660 was identified as mating type 1 and KFI615 as mating type 2. Pathogenicity tests showed that both isolates caused ear and stalk rot diseases on corn (unpublished data). To confirm the identity of the two fungal isolates, portions of three housekeeping genes, encoding beta-tubulin (Tub2), translation elongation factor (Tef1), and the second largest subunit of RNA polymerase II (Rpb2), were amplified by PCR from KFI615 and KFI660, following the method of Fumero et al. (2020). DNA sequences consisting of partial sequences of Tub2, Tef1, and Rpb2 were concatenated for each isolate and were combined with those from $13 \mathrm{~F}$. temperatum isolates, six F. subglutinans isolates, and one $F$. proliferatum isolate previously studied by Fumero et al. (2020). The resulting combined data set was subjected to phylogenetic analysis with the maximum likelihood algorithm implemented in MEGAX (Kumar et al. 2018), with the Tamura-Nei substitution model and 1,000 bootstrap replicates. The phylogeny tree showed that KFI615 and KFI660 clustered with all other isolates of $F$. temperatum, supported by a bootstrap value of $94 \%$ (Supplementary Fig. S1). These two F. temperatum isolates were deposited in the Culture Collection of the Warsaw Agricultural University Herbarium (WAUF), Warsaw, Poland.

To sequence whole genomes, high-molecular weight DNA samples were extracted from mycelia of KFI615 and KFI660 using DNeasy plant mini kit (Qiagen), following the manufacturer manual. One paired-end (average insert sizes of $350 \mathrm{bp}$ ) library was prepared for each isolate and subjected to 100-bp paired-end sequencing, using the BGISeq500 platform at BGI (Cambridge, MA, U.S.A.). A total of $110,319,180$ clean reads (11.03 Gb) were generated for KFI615 and 116,335,522 clean reads (11.63 Gb) for KFI660. After removing poor-quality reads, sequences were assembled using ABySS v2.0 (Jackman et al. 2017), 
yielding a draft genome that consisted of 4,689 contigs for KFI615 and 5,615 contigs for KFI660. The contigs generated by ABySS were further assembled into 20 and 18 scaffolds for the two isolates, using software RaGoo (Alonge et al. 2019), with default parameters and F. temperatum CMW40964 genome sequence as reference (GenBank accession number GCA_001513835.1) (Wingfield et al. 2015). The draft genome assemblies of KFI615 and KFI660 had 98.9 and $99.0 \%$ completeness, respectively, according to the evaluations with BUSCO v4.1.2 (against ascomycota_odb10) (Seppey et al. 2019). The GC content was $46.34 \%$ for KFI615 and $46.67 \%$ for KFI660 (Table 1).

Protein-coding genes were predicted using AUGUSTUS v 3.1.3 (Hoff and Stanke 2013) after training with the gene models of $F$. graminearum $\mathrm{PH}-1$ (King et al. 2015). The KFI615 isolate contained 14,067 putative genes, while the KFI660 isolate had 13,994 putative genes. BLASTn search detected the genes for MAT1-1-1 and MAT1-1-2 in KFI660 and for MAT1-2-1 and MAT1-2-2 in KFI615, confirming that these two isolates are of opposite mating types. $A$ complete gene cluster (Bea1, Bea2, Bea3, and Bea4) for beauvericin biosynthesis (Niehaus et al. 2016) was discovered in both genome sequences, as has been found in the other sequenced isolate RC2914 (Fumero et al. 2020). The six genes homologous to carRA, carB, carT, carD, carO, and carX for carotenoid biosynthesis in Fusarium spp. (Avalos et al. 2017) were also identified in KFI615 and KFI660 genome sequences. These genes were presumably functional because both KFI615 and KFI660 were characterized as carotenoids producers (unpublished data). To identify putative carbohydrate-active enzymes (CAZyme), protein sequences predicted by AUGUSTUS were annotated using the dbCAN2 meta server (Zhang et al. 2018), resulting in 588 CAZymes for KFI615 and 586 CAZymes for KFI660. Using the anti-SMASH fungal version v 5.0 (Blin et al. 2019), 49 and 50 genes involved in biosynthesis of secondary metabolites were identified for KFI615 and KFI660, respectively. Secretome was analyzed with SignalP version 5.0 (Almagro Armenteros et al. 2019), and 1,471 and 1,474 secreted proteins were predicted for KFI615 and KFI660. Among the secreted proteins predicted, 328 in KFI 615 and 325 in KFI660 were classified as effector candidates, using EffectorP 2.0, with the score greater than 0.8 (Sperschneider et al. 2018) (Table 1). The genome resources will allow genome comparisons within the species and among members of the F. fujikuroi complex and contribute to our understanding of the molecular mechanisms underlying the pathogenicity and other biological properties of these important fungal pathogens.

Data availability. The partial sequences of Rpb2, Tef1, and Tub2 from F. temperatum isolates KFI615 and KFI660 have been deposited in the National Center for Biotechnology Information (NCBI) GenBank database with accession numbers MT786306, MT786307, MT786308, MT786309, MT791049, and MT791050. The genome sequences have been deposited into NCBI GenBank database with the BioProject accession number PRJNA643159. The Whole-Genome Shotgun accession number is JACOPY000000000 for KFI 615 and JACOPZ000000000 for KFI660.

\section{Literature Cited}

Almagro Armenteros, J. J., Tsirigos, K. D., Sønderby, C. K., Petersen, T. N., Winther, O., Brunak, S., von Heijne, G., and Nielsen, H. 2019. SignalP 5.0 improves signal peptide predictions using deep neural networks. Nat. Biotechnol. 37:420-423.

Alonge, M., Soyk, S., Ramakrishnan, S., Wang, X., Goodwin, S., Sedlazeck, F. J., Lippman, Z. B., and Schatz, M. C. 2019. RaGOO: Fast and accurate referenceguided scaffolding of draft genomes. Genome Biol. 20:224.

Avalos, J., Pardo-Medina, J., Parra-Rivero, O., Ruger-Herreros, M., Rodríguez-Ortiz, R., Hornero-Méndez, D., and Limón, M. C. 2017. Carotenoid biosynthesis in Fusarium. J. Fungi (Basel) 3:1-16.

Blin, K., Shaw, S., Steinke, K., Villebro, R., Ziemert, N., Lee, S. Y., Medema, M. H., and Weber, T. 2019. antiSMASH 5.0: Updates to the secondary metabolite genome mining pipeline. Nucleic Acids Res. 47 (W1):W81-W87.

De Vos, L., Steenkamp, E. T., Martin, S. H., Santana, Q. C., Fourie, G., van der Merwe, N. A., Wingfield, M. J., and Wingfield, B. D. 2014. Genome-wide macrosynteny among Fusarium species in the Gibberella fujikuroi complex revealed by amplified fragment length polymorphisms. PLoS One 9: e114682.
Desjardins, A. E. 2006. Fusarium Mycotoxins: Chemistry, Genetics, and Biology. APS Press, St. Paul, MN, U.S.A.

Fumero, M. V., Villani, A., Susca, A., Haidukowski, M., Cimmarusti, M. T., Toomajian, C., Leslie, J. F., Chulze, S. N., and Moretti, A. 2020. Fumonisin and beauvericin chemotypes and genotypes of the sister species Fusarium subglutinans and Fusarium temperatum. Appl. Environ. Microbiol. 86:e00133-2.

Hoff, K. J., and Stanke, M. 2013. WebAUGUSTUS-A web service for training AUGUSTUS and predicting genes in eukaryotes. Nucleic Acids Res. 41: W123-W128.

Jackman, S. D., Vandervalk, B. P., Mohamadi, H., Chu, J., Yeo, S., Hammond, S. A., Jahesh, G., Khan, H., Coombe, L., Warren, R. L., and Birol, I. 2017. ABySS 2.0: Resource-efficient assembly of large genomes using a Bloom filter. Genome Res. 27:768-777.

King, R., Urban, M., Hammond-Kosack, M. C. U., Hassani-Pak, K., and HammondKosack, K. E. 2015. The completed genome sequence of the pathogenic ascomycete fungus Fusarium graminearum. BMC Genomics 16:544.

Kumar, S., Stecher, G., Li, M., Knyaz, C., and Tamura, K. 2018. MEGA X: Molecular evolutionary genetics analysis across computing platforms. Mol. Biol. Evol. 35: 1547-1549. 
Kvas, M., Marasas, W. F. O., Wingfield, B. D., Wingfield, M. J., and Steenkamp, E. T. 2009. Diversity and evolution of Fusarium species in the Gibberella fujikuroi complex. Fungal Divers. 34:1-21.

Ma, L.-J., Geiser, D. M., Proctor, R. H., Rooney, A. P., O'Donnell, K., Trail, F., Gardiner, D. M., Manners, J. M., and Kazan, K. 2013. Fusarium pathogenomics. Annu. Rev. Microbiol. 67:399-416.

Moretti, A., Mulé, G., Ritieni, A., Láday, M., Stubnya, V., Hornok, L., and Logrieco, A. 2008. Cryptic subspecies and beauvericin production by Fusarium subglutinans from Europe. Int. J. Food Microbiol. 127:312-315.

Niehaus, E. M., Studt, L., von Bargen, K. W., Kummer, W., Humpf, H. U., Reuter, G., and Tudzynski, B. 2016. Sound of silence: The beauvericin cluster in Fusarium fujikuroi is controlled by cluster-specific and global regulators mediated by H3K27 modification. Environ. Microbiol. 18:4282-4302.

O'Donnell, K., Cigelnik, E., and Nirenberg, H. I. 1998. Molecular systematics and phylogeography of the Gibberella fujikuroi species complex. Mycologia 90:465-493.

Scauflaire, J., Gourgue, M., and Munaut, F. 2011. Fusarium temperatum sp. nov. from maize, an emergent species closely related to Fusarium subglutinans. Mycologia 103:586-597.
Seppey, M., Manni, M., and Zdobnov, E. M. 2019. BUSCO: Assessing genome assembly and annotation completeness. Methods Mol. Biol. 1962:227-245.

Sperschneider, J., Dodds, P. N., Gardiner, D. M., Singh, K. B., and Taylor, J. M. 2018. Improved prediction of fungal effector proteins from secretomes with EffectorP 2.0. Mol. Plant Pathol. 19:2094-2110.

Steenkamp, E. T., Wingfield, B. D., Desjardins, A. E., Marasas, W. F. O., and Wingfield, M. J. 2002. Cryptic speciation in Fusarium subglutinans. Mycologia 94:1032-1043.

Wingfield, B. D., Barnes, I., Wilhelm de Beer, Z., De Vos, L., Duong, T. A., Kanzi, A. M., Naidoo, K., Nguyen, H. D., Santana, Q. C., Sayari, M., Seifert, K. A., Steenkamp, E. T., Trollip, C., van der Merwe, N. A., van der Nest, M. A., Markus Wilken, P., and Wingfield, M. J. 2015. IMA Genome-F 5: Draft genome sequences of Ceratocystis eucalypticola, Chrysoporthe cubensis, C. deuterocubensis, Davidsoniella virescens, Fusarium temperatum, Graphilbum fragrans, Penicillium nordicum, and Thielaviopsis musarum. IMA Fungus 6:493-506.

Zhang, H., Yohe, T., Huang, L., Entwistle, S., Wu, P., Yang, Z., Busk, P. K., Xu, Y., and Yin, Y. 2018. dbCAN2: A meta server for automated carbohydrate-active enzyme annotation. Nucleic Acids Res. 46:W95-W101. 